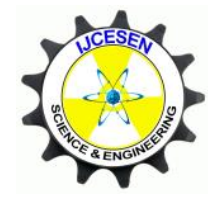

Copyright (C) IJCESEN
International Journal of Computational and

Experimental $\boldsymbol{S}$ cience and Engineering

(IJCESEN)

Vol. 3-No.1 (2017) pp. 44-46

http://iakkurt.dergipark.gov.tr/ijcesen

Research Article

\title{
Open-Hole Tensile Experiments of Thermoplastic Composite Laminates and Finite Element Analysis
}

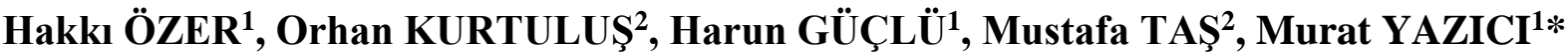 \\ ${ }^{1}$ Uludağ University, Engineering Faculty, Automotive Engineering Department, 16059, Bursa-Turkey \\ ${ }^{2}$ R\&D Center, Rollmech Automotive, Bursa/TURKEY \\ * Corresponding Author: myazici@uludag.edu.tr \\ (First received 25 November 2016 and in final form 20 December 2016) \\ \# Presented in " $3^{\text {rd }}$ International Conference on Computational and Experimental Science and Engineering (ICCESEN-2016)"
}

\section{Keywords}

Thermoplastic Composite

Mechanical properties

Open-hole tensile test

FEA

\begin{abstract}
Composites materials are used in automotive industry for their light weight and high strength properties. With the progress signed in a new polymer matrix, recyclable thermoplastic composite (TPC) materials, became an excellent alternative to conventional materials. In this paper glass fiber reinforced TPC materials manufactured with lamina sequence techniques of polyamide, polypropylene matrix materials were used to realize open hole tensile tests. Finite Element Analysis (FEA) were also performed by using commercial software. The open-hole tensile tests results were compared with standard tensile tests results to clarify circular hole influence on the stress-strain behavior of the TPC materials. FEA results were also compared with the experimental data.
\end{abstract}

\section{Introduction}

Composite structures are widely using in the industry. In this reason, joining works has been making with alternative bonding techniques. Some of this techniques have been dissatisfying manufacturers in the way of cost-effectiveness. Standard joining techniques have a great impact on composite structures. Many researchers have been releasing work on bonding composite to metallic structures. Strength loss on the composite structures occurs with notch effect has been seen [1-4]. Works are making for determining and minimizing the stress distribution parameters. Different fiber sequence and different ply stacking of open-hole composite laminate, stress distribution around the hole, stress and damage behaviors of composite laminate have been investigated with using experiments and Finite Element (FE) method [5]. According to open hole tensile tests realizing on the same composite laminates, cause differences in stress levels and damage behaviors' on composite laminates have been observed depending on changing the radius of the hole [6-9]. Abisset et al. have investigated the change of failure stress values of carbon/epoxy laminate having $\left[45_{\mathrm{m}} / 90_{\mathrm{m}} /-\right.$ $\left.45_{\mathrm{m}} / 0_{\mathrm{m}}\right]_{\mathrm{ns}}$ fiber direction by increasing hole radius using experimental and FE method. While failure stress values decreasing layouts of $m=1$ and $n=4$ laminate, failure stress values rising in layouts of $\mathrm{m}=4, \mathrm{n}=1$ has been observed [10].

In this study, open-hole tensile tests of glass fiber (GF) reinforcement thermoplastic (Polyamide, Polypropylene) composite having [45/90] lamina orientations was executed. Open-hole tensile test results were compared with standard tensile test results. Open-hole effect on maximum stress levels and stress concentration of the composite laminate having $[45 / 90]_{7}$ fiber ply orientations were performed by experimentality.

\section{Materials And Methods}

In this study, three different composite test samples thermoplastic based PP and PA glass fiber reinforcement composites were used for the openhole tensile test to determine the chart decision under the quasi-static load. FEA was realized using Abaqus/Standard software. 


\subsection{Experimental Set-up}

Glass fibers were manufactured by stacking sequence of $[0 / 90]_{7}$. Matrix materials of PP and PA were used for Glass fiber reinforcement thermoplastic composite specimens. Figure 1 illustrates the stacking sequence of glass fibers. Open-hole tensile test coupons that made of thermoplastic composite materials were prepared properly according to ASTM D3039 standard. Tabs were stuck on ends of the thermoplastic specimens that not to be damaged by grips during the tensile tests. The DP8005 adhesive that made by the 3M Corporation were used for the bonding process. Tensile tests were conducted on Zwick Proline Z010 $\mathrm{TH}$ tensile machine. Tests were executed on $10 \mathrm{~mm} / \mathrm{min}$ constant crosshead velocity. Figure 2 shows the open-hole tensile tests on Zwick Proline Z010 TH tensile machine.

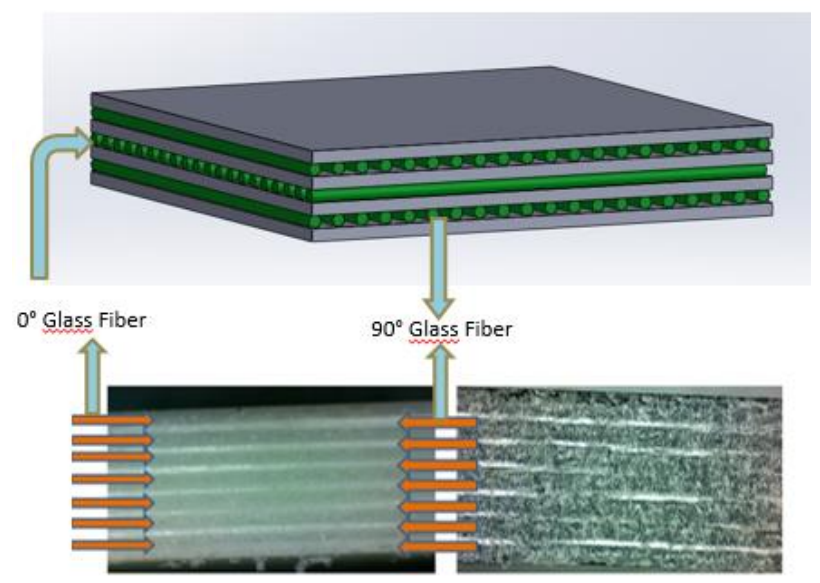

Figure 1. Stacking sequence of thermoplastic composite specimens

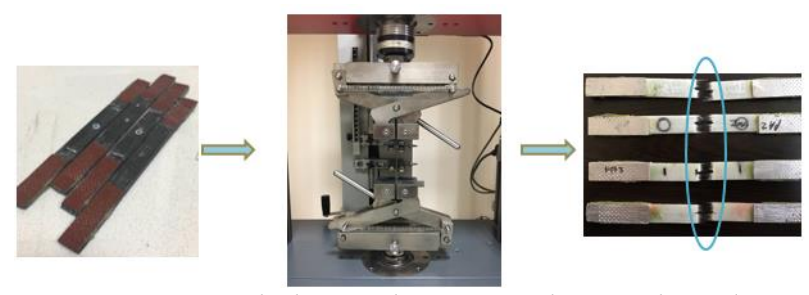

Figure 2. Open-hole tensile tests on the Zwick Proline Z010 TH tensile machine.

\subsection{Numerical Set-up}

FE model of test specimens was set up by using Abaqus software with 4692 Quadrilateral shell elements. Material constants of composite materials were taken from results of tensile, compression, three points bending and shear tests. Figure 3 shows an FE model of the open-hole tensile zone. Elastic properties of PA lamina were given in Table 1.

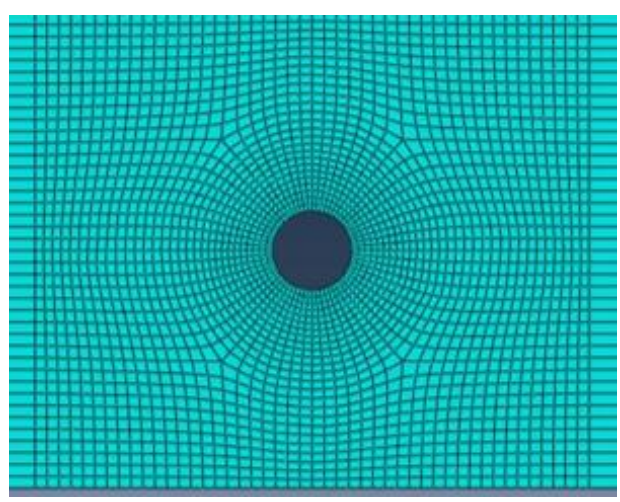

Figure 3. FE model of the open-hole tensile zone.

Table 1. Elastic properties of PA lamina

\begin{tabular}{|c|c|c|c|c|c|c|}
\hline $\begin{array}{c}\text { Density } \\
\left(\mathrm{g} / \mathrm{cm}^{3}\right)\end{array}$ & $\mathbf{E}_{\mathbf{1 1}}$ & $\mathbf{E}_{\mathbf{2 2}}$ & $\mathbf{G}_{\mathbf{1 2}}$ & $\mathbf{G}_{\mathbf{1 3}}$ & $\mathbf{G}_{\mathbf{2 3}}$ & $\boldsymbol{v}_{\mathbf{1 2}}$ \\
\hline 1.39 & 60 & $\mathrm{GPa}$ & $\mathrm{GPa}$ & $\mathrm{GPa}$ & $\mathrm{GPa}$ & $(-)$ \\
\hline
\end{tabular}

\section{Results and Discussions}

Figure 4 illustrates the stress-strain curves of PA and PP composite materials also shows standard tensile tests and open-hole tensile tests comparison [11]. When analyzed the stress-strain curves, interface compatibility between PA matrix and fiber more efficient than PP matrix has been seen. Accordingly, high strength value was obtained in PA thermoplastic composite standard and open-hole tensile tests. Stress concentration generation around the hole during open-hole tensile experiments caused nearly $15 \%$ strength loss compared to standard test results. This figure also showed that a small hole in the center of specimens changed the stress-strain behavior of the coupon by letting elongation latitude. Figure 5, shows stress concentration around hole and deformation of the hole during the open-hole tensile test. The same deformations with the experiments were obtained in the open-hole tensile test FE simulations.

\section{Conclusions}

In this study, open-hole tensile tests of glass fiber reinforced thermoplastic composites having $[45 / 90]_{7 \mathrm{~s}}$ fiber direction was realized. Deformation at the around of the hole was examined by FE method. The open-hole tensile tests results were compared with standard tensile tests results. A strength loss because of stress concentration around the hole in having [0/90] fiber direction laminates was observed. 


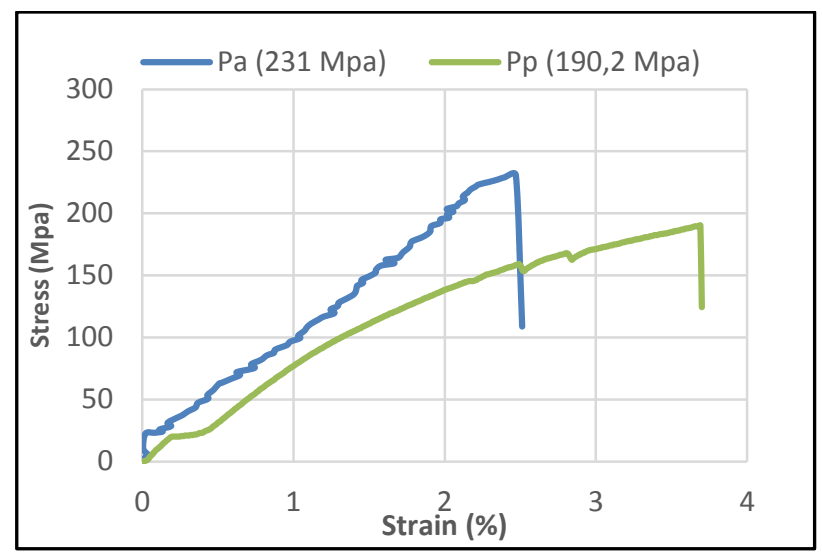

a)

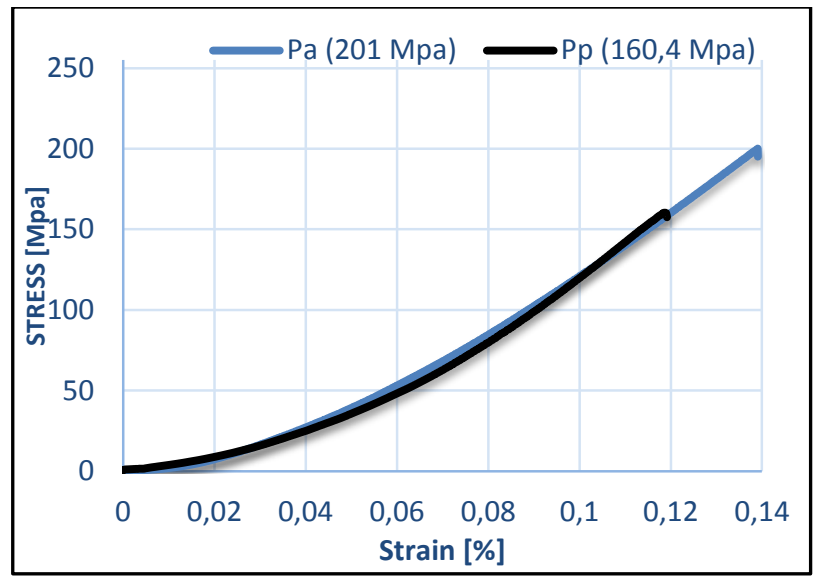

b)

Figure 4. Results of the $[0 / 90]_{7}$ laminated PA/GF and $\mathrm{PP} / \mathrm{GF}$ composites a) standard tensile tests b) open-hole tensile tests [11].

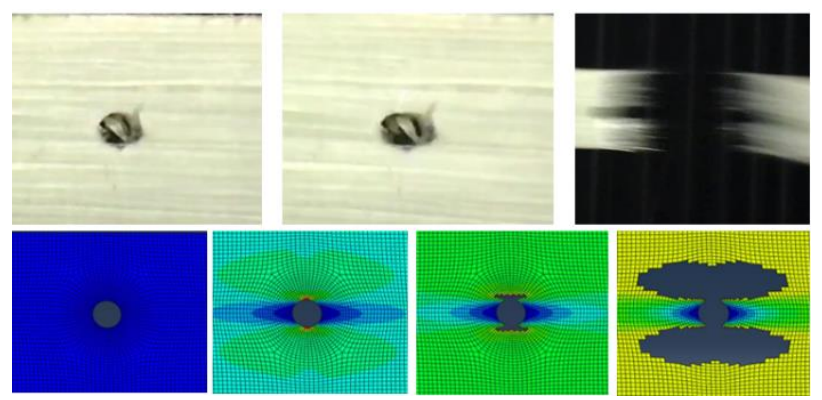

Figure 5. Results of experiments and simulations of PA composite.

The hole in the center of the test specimens changed the stress-strain behavior and elastic modulus of the TPCs.

\section{References}

[1] E. Martin, D. Leguillon, N. Carrere, An Extension of The Point-Stress Criterion Based On a Coupled Stress and Energy Fulfilment: Application to The Prediction of The Open-Hole Tensile Strength Of A Composite Plate, Structural Integrity and Durability of Advanced Composites, (2015) 425-444. DOI:10.1016/B978-0-08-100137-0.00017-1
[2] B. G. Green, M. R. Wisnom, S. R. Hallett, An Experimental Investigation into the Tensile Strength Scaling of Notched Composites. Composites Part A: Applied Science and Manufacturing, 38 (2007) 867 878. DOI:10.1016/j.compositesa.2006.07.008

[3] T.E. Tay, G. Liu, V.B.C. Tan, Damage Progression in Open-Hole Tension Laminates by the SIFT-EFM Approach. Journal of Composite Materials. 40 (2006) 971-992. DOI:10.1177/0021998305056386

[4] L.J. Hart-Smith Design and Analysis of Bolted and Riveted Joints in Fibrous Composite Structures. Recent Advances in Structural Joints and Repairs for Composite Materials. (2003) 211-254. DOI:10.1007/978-94-017-0329-1_7

[5] B. Hongchen, L. Guangyan, Progressive Failure Analysis On Scaled Open-Hole Tensile Composite Laminates. Composite Structures. 150 (2016) 173180. DOI:10.1016/j.compstruct.2016.05.017

[6] G.H. Erçin, P.P. Camanho, J. Xavier, G. Catalanotti, S. Mahdi, P. Linde. Size Effects On the Tensile and Compressive Failure of Notched Composite Laminates. Composite Structures. 96 (2013) 736744. DOI:10.1016/j.compstruct.2012.10.004

[7] B.Y. Chen, T.E. Tay, P.M. Baiz, S.T. Pinho, Numerical Analysis of Size Effects On Open Hole Tensile Composite. Composite Part A. 47 (2013) 5262. DOI:10.1016/j.compositesa.2012.12.001

[8] F.P. Van der Meer, L.J. Sluys, S.R. Hallet, M.R. Wisnom, Computational Modeling of Complex Failure Mechanisms in Laminates. Journal Of Composite Materials. 46 (2012) 603-623. DOI: $10.1177 / 0021998311410473$ 10.1016/j.compositesa.2009.02.021

[9] S.R. Hallet, B.G. Green, W.G. Jiang, M.R. Wisnom, An Experimental and Numerical Investigation into the Damage Mechanisms in Notched Composites. Composites Part A: Applied Science and $\begin{array}{llll}\text { Manufacturing. } & 40 \quad \text { (2009) 613-625. }\end{array}$ DOI:10.1016/j.compositesa.2009.02.021

[10] E. Abisset, F. Daghia, P. Ladevèze, On The Validation of a Damage Mesomodel for Laminated Composites by Means of Open-Hole Tensile Tests On Quasi-Isotropic Laminates. Composites: Part A. 42 (2011) 1515-1524.

DOI:10.1016/j.compositesa.2011.07.004

[11] M. Yazıc1, H. Özer, İ.Karen, C. Torçuk, Mechanical Properties of 2D Cross-Ply E-Glass Fiber Reinforced Thermoplastic Laminated Composite Materials. Advances in Civil, Structural and Mechanical Engineering. (2016) 90-94. DOI: 10.15224/978-1-63248-093-4-77 